\title{
ENTRE-VISTA(S): INTERACÕES SEMIÓTICAS COM ANALICE DUTRA PILLAR, MOEMA MARTINS REBOUÇAS E MURILO SCÓZ
}

Sandra Ramalho e Oliveira ${ }^{1}$ 
Na condição de editora do número 22 da Revista Palíndromo, decidi apresentar uma entrevista múltipla, uma entre-vista(s). Primeiro, porque gostaria de dialogar com essas várias pessoas mesmo, mas a chance de se fazer uma entrevista para uma revista científica é rara. Não conseguiria, uma por ano, dar conta de todos. No número 10, entrevistei Ana Claudia de Oliveira (PUC/SP), minha orientadora de doutorado, mas agora gostaria de trazer pessoas ligadas à semiótica, sim, mas mais próximas do ensino e do ensino de arte ou da semiótica do cotidiano. Queria ouvir Analice Dutra Pillar, Professora Titular da Faculdade de Educação da Universidade Federal do Rio Grande do Sul/UFRGS, atuando na graduação e na pós-graduação, com vários livros publicados e editora da Revista GEARTE; Moema Lúcia Martins Rebouças, Professora Titular da Universidade Federal do Espírito Santo/UFES, igualmente com atuação na graduação e pós-graduação e com várias publicações, além de membro de sociedades de ensino e pesquisa no país e no exterior; e Murilo Scóz, Professor Efetivo da UDESC, atuando na graduação em Design e na pós-graduação em Design e em Moda, líder do Grupo de Pesquisa UDESC/CNPq NEST, Núcleo de Estudos Semióticos Transdisciplinares. Como explicar, explicitar ou mesmo, como denominar essa ideia de entrevista múltipla? Semioticamente, poderia dizer que se trata de um quadrado, o quadrado semiótico, quatro pontos, os três colegas e eu; mas aqui ninguém seria oposição semântica, no máximo estaríamos gravitando na elipse semiótica, em torno dos sentidos. Pensei em justificar com as interações arriscadas, onde os acidentes dar-se-iam em virtude de ser uma entrevista tríplice, inesperada. Mas resolvi justificar mesmo pela arte e sua ânsia do inusitado, do creare, do produzir o que não existe. $E$ do ensino de arte mesmo, que visto ainda pelos preconceituosos como convencional e padronizado, igualmente tem ânsias de infinito, de sonhar o impossível e de, ao menos, humildemente acompanhar e dialogar com os sentidos do cotidiano de hoje em dia, com suas tecnologias, angústias, crises de identidade e incertezas quanto ao futuro. E vamos ouvir, então, nossos colegas semioticistas, com quem partilho o espaço de intersecção onde se encontram arte, semiótica e educação? 
Sandra Ramalho - A Revista Palíndromo número 22, repetindo o escopo teórico que procurou motivar as reflexões publicadas no seu número 10, volta trazendo a semiótica para interagir com a arte e, se possível, mais especificamente, com o ensino de arte. Ainda são poucos os pesquisadores que atuam nesse campo de intersecção arte/semiótica/educação, ou vocês conseguem entrever outras realidades, considerando os seus respectivos pontos de vista?

Analice Pillar - Até onde conheço, as pesquisas que abordam as relações entre artes visuais/semiótica discursiva/ensino da arte começam, de modo sistemático, no Centro de Pesquisas Sociossemióticas (CPS), com as pesquisas de Sandra Ramalho e Oliveira, Moema Rebouças, Anamélia Buoro e Lucimar Bello. Foi Ana Claudia de Oliveira, grande difusora da semiótica discursiva, que desde a década de 1990 vem orientando, animando e possibilitando estudos nesse campo de conhecimento. $\mathrm{Na}$ Universidade Federal do Rio Grande do Sul (UFRGS), as professoras Maria da Graça Krieger, Maria Lilia Dias de Castro, Elizabeth Duarte e Dinorá Fraga, já nos anos de 1980 e 1990, tinham a semiótica discursiva como aporte em suas pesquisas nas áreas da linguística, da comunicação e da educação. E, em 1980, a professora lone Bentz, foi uma das precursoras nas pesquisas em semiótica discursiva na UFRGS e depois na Universidade do Vale do Rio dos Sinos (UNISINOS), onde desenvolve e orienta pesquisas nas áreas da semiótica discursiva, da linguística e da comunicação. Especificamente no campo do ensino de artes visuais, no Brasil, pode-se constatar três núcleos que abordam as relações entre arte/semiótica/educação em pesquisas de mestrado e de doutorado. Tais núcleos estão na Universidade do Estado de Santa Catarina (UDESC), com Sandra Ramalho e Oliveira; na Universidade Federal do Espírito Santo (UFES), com Moema Rebouças; e na Universidade Federal do Rio Grande do Sul (UFRGS), com Analice Dutra Pillar. A partir desses núcleos, se disseminaram estudos e práticas para outros lugares e instituições.

Moema Rebouças - Considerando que foi em 1998 no Programa de Pós-Graduação em Comunicação e Semiótica da PUC/SP a defesa da primeira tese ${ }^{1} \mathrm{com}$ a intersecção arte/semiótica greimasiana/educação, estes 20 anos, em comparação com outras bases teóricas já estabelecidas, foram de grande repercussão, como constam nos dados de uma pesquisa realizada durante o ano de 2016 e publicada nos Anais do Colóquio Internacional Greimas², em 2017 em comemoração ao centenário do fundador desta semiótica. O objetivo da investigação exploratória foi o de realizar um levantamento em várias áreas, mas o nosso Grupo de Pesquisa GEPEL ${ }^{3}$ dedicou-se aos estudos na área de educação para selecionar as pesquisas que têm na semiótica de Greimas seu arcabouço teórico-metodológico, como ele foi empregado e o alcance dos usos. Como o ponto de partida foi o da Educação, os programas de pós-graduação emergem com o maior número de pesquisas, 53 ao todo. Contudo, o número de pesquisas em outras campos do saber é muito expressivo, 39 trabalhos,

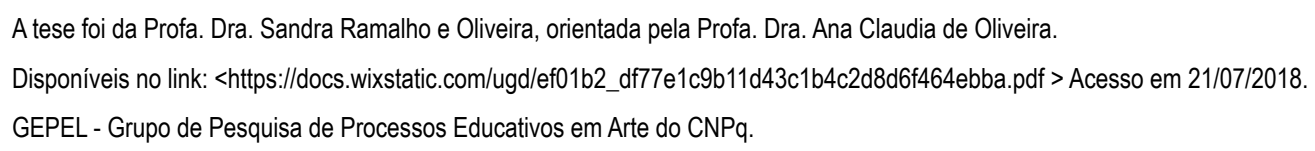


concentrados em programas de Artes e de Comunicação e Semiótica. Considerando os periódicos, os dados apontaram para 8 revistas científicas e um total de 22 artigos, entre elas as de maior expressividade em publicações foram a GEARTE-Revista do Grupo de Pesquisa em Educação e Arte do Programa de Pós-Graduação em Educação da UFRGS; e a Palíndromo-Revista do Programa de Pós-Graduação em Artes Visuais do Centro de Artes da UDESC. Sendo que a primeira revista foi lançada em 2014, e a segunda em 2010, com acesso digital a partir de 2012. Portanto, em tão pouco tempo para se estabelecer como campo teórico metodológico nas intersecções arte/semiótica/educação, os pesquisadores que a partir de 1998 "adotaram" esta semiótica em suas formações têm exercido um papel de difusores desta teoria e produzido pesquisas que articuladas com as mídias, com a tecnologia, com a experiência estética e com os materiais destinados à escola, como os livros infantis, apontam para uma compreensão de como nas práticas educativas vividas na escola, se encontram imersas as práticas sociais vividas no cotidiano.

Murilo Scóz - Pelas particularidades do campo do Design, que estabelece conexões intrincadas com diferentes linguagens artísticas, é necessário em primeiro lugar reconhecer a pertinência da análise dos artefatos projetados - bem como dos processos projetuais - que tem na semiótica de Greimas sua base conceitual. Sem se confundir com a ideia de mera arte aplicada, ou mesmo de uma "arte menor", o Design se constitui enquanto prática de configuração e reflexão sobre o mundo artificial, o que permite aos semioticistas tomá-lo como linguagem. Em outras palavras, assim como outras atividades humanas com uma dimensão estética, também podemos reconhecer no Design a lógica de um sistema produtor de sentido operado pelo seu autor, o designer. Esta constatação está na base de uma semiótica do Design, razão pela qual podem-se reconhecer, em especial no Brasil, diferentes iniciativas de análise de projetos, artefatos, interfaces, marcas, etc., em que pese a hegemonia da perspectiva americana. Sem surpresa, os maiores eventos científicos de Design no país (como o P\&D Design, o CIDI, o Ergondesign e o IDEMI) recebem um número substancial de trabalhos sobre o fenômeno da significação, tendo como eixo teórico as categorias sígnicas de Peirce. Ainda aguardando publicação, um amplo estudo de revisão bibliográfica realizado pelos membros do ateliê em Design do CPS (Centro de Pesquisas Sociossemióticas) em parceria com o NEST (Núcleo de Estudos Semióticos e Transdisciplinares da UDESC) demonstrou, ainda em 2016, o crescimento significativo das pesquisas em Design pela visada greimasiana. Neste levantamento, pode-se observar não apenas o incremento quantitativo nas pesquisas, mas uma importante descentralização das iniciativas rumo a novos centros de ensino de Design. Além dos resultados bibliométricos expressivos em termos de artigos publicados em periódicos, cumpre destacar as monografias já defendidas nas pós-graduações em Design no país, que nos últimos 3 anos somaram 24 trabalhos entre teses e dissertações. Quanto às novas perspectivas do campo, é de grande relevância o movimento de aproximação entre Design e Semiótica Greimasiana que vem sendo desenvolvido em nosso programa de mestrado em Métodos para Fatores Humanos, bem como no mestrado profissional em Design do Vestuário e Moda, ambos da UDESC. E justamente pela institucionalização de disciplinas de semiótica nas grades curriculares tanto dos programas quanto das graduações a eles associadas. 
Sandra Ramalho - É certo que as teorias semióticas são complexas e mesmo que é difícil situar os iniciantes - ou debutantes, como diria Eric Landowski - no mapa das semióticas, para então compreenderem de que semiótica se fala. Qual a sua percepção dessa espécie de temor respeitoso que os leigos têm da semiótica?

Moema Rebouças - Fundamentada em uma metalinguagem "pesada", com dois dicionários básicos de seus termos e conceitos, a semiótica parece estar destinada a poucos, mesmo na academia. Por outro lado, a associação ao projeto estruturalista no interior do qual ela surgiu, é um outro argumento utilizado, para os que alegam que esta base teórica desconsidera o contexto, a história e o social. Esta argumentação tem base nos estudos iniciais do texto, e da ênfase nos mecanismos estruturais textuais, contudo a semiótica sempre reconheceu que o texto se produz num dado contexto histórico.

Vencidas estas duas barreiras, o iniciante, independente da área em que atua encontrará uma fundamentação consistente para compreender em seus próprios campos a significação, tanto da análise como da constituição dos objetos e dos sentidos produzidos. É Landowski ${ }^{4}(2017, p .69)$ que nos diz que podemos empregar os conceitos da disciplina, sem nos tornarmos escravos de seu léxico. As pesquisas desenvolvidas nos programas de pós-graduação em educação e em artes, que são o foco desta entrevista, têm cumprido este papel de formação e disseminação da semiótica enfrentando o temor dos iniciantes e a complexidade da teoria, com o encantamento decorrente da apropriação teórica e conceitual revelada nos estudos produzidos.

Murilo Scóz - Creio que em parte esta dificuldade esteja ligada à linguagem própria das análises dos semioticistas, no uso das categorias terminológicas que, por zelo, precisam ser aplicadas com muito rigor. Sem este nível de precisão, uma teoria que pretende dar conta do processo da produção de sentido, reclamando para si um alto grau de cientificidade, fracassaria em seu projeto. Em outras palavras, parece uma dificuldade insuperável. Contudo, não passa despercebido o enorme esforço que grandes semioticistas tem empreendido no sentido de aproximar a semiótica das práticas sociais vividas, buscando construir categorias tanto mais elásticas quanto mais afeitas à experiência real dos sujeitos do mundo. Isto cobra que a metalinguagem semiótica seja tensionada, ou melhor, flexibilizada, mas sobretudo coloca o semioticista em contato direto com os fenômenos significantes, o que obriga também a refletir sobre a própria condição da análise.

Por outro lado, e imaginando que tais movimentos de análise precisam preservar o rigor metodológico e a sua validade enquanto produção de um olhar científico sobre o mundo significante, é igualmente desafiador fazer com que a semiótica revele seu potencial, ou seja, que faça saber (por meio dos discursos que produz de si mesmo) a estes enunciatários "leigos", sua aplicabilidade. Não se trata de diminuir aqui a discussão à utilidade da teoria, mas de permitir, por meio destes desenvolvimentos conceituais, que a teoria seja experimentada em sua potência, enquanto uma semiótica viva, dinâmica e relevante diante da complexidade das práticas sociais. 
Analice Pillar - Tenho observado duas atitudes por parte das pessoas que querem conhecer a teoria semiótica discursiva: a primeira diz respeito à terminologia e ao denso corpus teórico que as assusta; e a segunda, é uma curiosidade acerca das possibilidades de análise de distintos textos que ela possibilita. A terminologia, em especial os conceitos da área da linguística, é bastante complexa e de difícil compreensão para quem não é da área; bem como o modo de descrição e análise dos textos e das ações cotidianas que a teoria propõe. No entanto, é grande o interesse em conhecer uma teoria que procura analisar como se dá a produção e a apreensão de efeitos de sentido em diferentes textos e práticas. Esse interesse pela semiótica leva, muitas vezes, aqueles que querem se iniciar na teoria, por desconhecerem as diferentes semióticas e suas abordagens, a um amálgama dos aportes teóricos dessas abordagens. Diferenciar as semióticas peirceana, discursiva e da cultura, suas origens e seus objetos de estudo é fundamental para entender os pressupostos teóricos e metodológicos dessas diversas linhas. Em relação à semiótica discursiva, quando começamos a conhecê-la, ela passa a ser um modo de ver o mundo, de entender que tudo tem um sentido, que nada está por acaso em uma produção imagética, por exemplo. María Acaso5, ao tratar da leitura de produções visuais e audiovisuais no ensino da arte, observa que é importante unir a semiótica com a pedagogia, as artes e a cultura visual. A autora ressalta que no ensino da arte o interesse pela semiótica não se centra em desenvolver um manual de semiótica visual para professores, mas em que se entenda as produções imagéticas e o trabalho docente como uma sucessão de atos que configuram um discurso, o qual pode ser analisado do ponto de vista de seus efeitos de sentido.

Sandra Ramalho - Definida a escolha da vertente teórica semiótica, ainda assim resta a dúvida até quanto à sua denominação: semiótica discursiva? Sociossemiótica? Semiótica das situações? Semiótica das práticas? Semiótica dos sentidos? Semiótica landowskiana? Semiótica pós-greimasiana, como Landowski se referiu em um dos últimos colóquios do CPS? Ou semiótica sem nome, sugerido indiretamente pelo mesmo teórico no seu livro Passions sans nom (2004)? Muitas sutilezas nas diferenças entre as denominações...

Murilo Scóz - Na verdade, uma leitura epistemológica dessa questão nos guia por encadeamentos também não muito claro, visto que não se trata de um mapeamento que se possa construir como uma linha reta, ou como uma sequência causal e coerente de eventos. É claro que existem marcos temporais importantíssimos, como a obra póstuma de Saussure (1916), o lançamento de Semântica Estrutural (Greimas, 1965), a retomada da fenomenologia no campo das ciências sociais durante o pós-guerra, o congresso da Associação Internacional de Semiótica de 1974 (em que se votou em assembleia pela unificação dos termos), bem como a publicação de $D a$ imperfeição, em 1987.

5 ACASO, María; PILLAR, Analice Dutra . Criando fluxos de investigações efervescentes entre Espanha e Brasil. Revista GEARTE, v. 1, n.1, p. 44-58, jan./abr. 2014 
Dito isso, parece muito adequada uma alegoria proposta por Landowski na obra Com Greimas, justamente ao refletir sobre e tentar definir este edifício teórico multiforme identificado por tantos nomes diferentes. Utilizando a metáfora da borboleta cabeça de Janus, Landowski sinaliza a importância de empregar as categorias da semiótica (suas bases conceituais), mas que ao mesmo tempo seja praticada, ou seja, confrontada sistematicamente com novos objetos. Assim, a semiótica que se desenha (e cujo nome aqui discutimos) está por se produzir em ato, exatamente através das pesquisas e das explorações em curso. Uma semiótica geral é, portanto, uma semiótica do devir, pois se estabelece na passagem entre a programação das categorias já propostas e o ajustamento com o mundo vivido. Como o deus romano das entradas, uma tal semiótica precisa conservar seu caráter sistemático sem perder a disponibilidade para o acaso.

Analice Pillar - Nos textos de autores referência na área da semiótica pode-se transitar tanto pelas denominações semiótica discursiva, semiótica greimasiana como semiótica francesa referindo-se à vertente da semiótica que tem por objeto a produção e a apreensão de efeitos de sentido. A partir dos dois últimos livros de Greimas, Da Imperfeição e Semiótica das Paixões, surgem duas vertentes da semiótica discursiva como desdobramento da teoria associadas a cada uma dessas obras, respectivamente, a sociossemiótica e a semiótica tensiva. A sociossemiótica vai se debruçar sobre as situações cotidianas com os estudos, especialmente, de Eric Landowski e de Ana Claudia de Oliveira no Centro de Pesquisas Sociossemióticas (CPS). E a semiótica tensiva vai abordar os estados de alma e as intensidades nas relações entre as pessoas e delas com os objetos, tendo nos estudos de Claude Zilberberg e Jacques Fontanille. Mais recentemente, Landowski propõe que além dos textos, que seriam objetos constituídos, a semiótica analise as práticas, situações em processo. Tal proposição visa dar continuidade à teoria e ao mesmo tempo ampliá-la. Daí as denominações semiótica das situações, semiótica das práticas, semiótica landowiskiana. Em relação aos trabalhos que inter-relacionam semiótica, educação e artes visuais há um predomínio dos estudos na área da sociossemiótica e, em especial nos estudos de Landowski e Ana Claudia de Oliveira.

Moema Rebouças - Como em outras ocasiões, e principalmente no livro Com Greimas: interações semióticas (2017), Landowski descreve como durante quase 20 anos desde a sua fundação, a semiótica greimasiana manteve o projeto de seu fundador coeso e unificado. Entretanto, com a morte de Greimas, o chamado "circulo greimasiano" composto de grupos de pesquisadores solidários, desdobrou-se em "unidades partitivas", conforme termo de Landowski (2017,p.62), sem entretanto perderem ou abandonarem o quadro epistemológico greimasiano de seu fundador. No Brasil convivem de modo cooperativo as abordagens da semiótica "tensiva" e da sociossemiótica. A primeira tem como propositores os teóricos Jacques Fontanille e Claude Zilberberg e a segunda, Eric Landowski. O que nos leva a concluir que o projeto é de continuidade teórica a partir da diversificação e da atualização dos estudos semióticos. Neste quadro nacional, as pesquisas com intersecção da arte/semiótica/ educação têm como principal base a sociossemitótica de Landowski, e as propostas 
da semiótica plástica iniciadas por Greimas, Jean Marie Floch e com continuidade nas pesquisas de Ana Claudia Oliveira, Sandra Ramalho e Oliveira, Anamélia Bueno Buoro, Analice Dutra Pillar e Moema Martins Rebouças, entre outros pesquisadores.

Sandra Ramalho - Particularmente, sou tributária das contribuições de Ana Claudia de Oliveira e, por meio dela, de Roman Jakobson, Jean-Marie Floch, Félix Tüllermann e Algirdas Julien Greimas para os estudos das imagens textuais, bi e tridimensionais, também ditas imagens fixas. Entretanto, estou convicta de que as proposições landowskianas consistem em um aparato teórico-metodológico que se ajusta - e a escolha semântica aqui não é ingênua - às demandas contemporâneas das investigações sobre o que se faz atualmente em nome da arte, em quaisquer de suas incaracterizáveis manifestações. Sintetizando, sei que as proposições dos regimes de interação e de sentidos não se destinam especificamente à arte, mas a todos os fenômenos de significação. Entretanto, coincidentemente - ou não, já que tem a ver com a vida cotidiana - , tais postulações consistem em um seguro modelo, no sentido semiótico do termo, para que se aborde a arte contemporânea. $O$ que vocês poderiam dizer a respeito?

Analice Pillar - Sem dúvida, as contribuições da semiótica plástica com os trabaIhos de Jean-Marie Floch e de Ana Claudia de Oliveira proporcionaram subsídios muito importantes para abordar a leitura de textos imagéticos, tanto da arte como da mídia e do cotidiano, ao enfocarem as qualidades plásticas sensíveis do plano da expressão. No que concerne à arte contemporânea, muitas produções solicitam um modo de relação com o público em que a participação é necessária, na maioria das vezes, para que a situação proposta aconteça. $O$ artista ao criar um trabalho propõe determinadas estratégias de interação e o participante, ao acolher esse convite para inter-atuar, passa a realizar certos procedimentos. Importa, então, entender que regimes de interação estão envolvidos nessas produções, como eles se evidenciam e que sentidos criam. O modelo teórico proposto por Landowski sobre os regimes de interação e sentido amplia os regimes da programação e da manipulação, estudados por Greimas, ao acrescentar os regimes do ajustamento e do acidente. Esse modelo possibilita entender como ocorrem nossas relações cotidianas com as outras pessoas e com os objetos. No caso das proposições da arte contemporânea podemos ter situações de interação programadas pelo artista em que há uma regularidade de procedimentos a serem realizados pelo participante. Já outras situações podem envolver diferentes estratégias intencionalmente propostas pelo artista de modo a conduzir o participante a realizar determinadas ações. Há, ainda, proposições que requerem uma interação através de um ajustamento sensível entre o participante e a situação apresentada. E proposições em que a interação pode ocorrer de modo acidental ou provocar uma fratura, um episódio inesperado. Esses regimes, no entanto, não são estanques e numa mesma proposição podem estar presentes diferentes modos de interação.

Moema Rebouças - Considero que os estudos da Arte não podem prescindir das bases da semiótica plástica propostas por Greimas, Oliveira e Floch, principalmente nas análises do plano de expressão constituidor da visualidade. Não importa 
se a análise da plasticidade começa pelos traços mínimos que compõem as figuras, ou pela apreensão das qualidades sensíveis que nos instaura no objeto, ou situação lida, o que no caso das artes inclui as instalações e performances, ou ainda pelos "blocos de significação" que podem ser decompostos. A ideia aqui é da possibilidade de apropriação da visualidade pela leitura do plano plástico. Contudo, as relações com a Arte, conforme argumenta Oliveira (1999) ${ }^{6}$ não devem estar restritas somente ao inteligível, mas às convocações multissensoriais entre o nosso corpo no corpo das obras. Desse modo, não basta compreender a Arte, tendo como passo metodológico a "leitura da Arte", mas de estar sensível e sentir o corpo da obra em presença. Por outro lado, a Arte Contemporânea ao diluir, ou redefinir as noções de artista, de público e de obra, propõe um outro modo de interação. $O$ artista não é somente o produtor, é também um propositor; o público não é só o espectador ou fruidor pois o "objeto artístico" pode desaparecer. A Arte nesta proposta contemporânea, tensiona a verticalidade tradicional entre artista e público para coautor, e de obra para prática, acontecimento. Neste momento os estudos propostos por Landowski serão importantes por possibilitar a análise dos acontecimentos em "ato" e os regimes de sentido convocados nestas interações. Tais práticas participativas, podem conter propostas que querem fazer-parecer-ser democráticas, mas não o são. Escondem ou se articulam a partir de estratégias de manipulação do público, ou estão programadas para fazer sentir. Se como objeto a ser "lido" e apreciado a semiótica a partir da abordagem do sensivel já dava conta de analisar a Arte, com a sociossemiótica e os regimes de sentido e de interação o campo de análise foi ampliado.

Murilo Scóz - Existem pelo menos dois aspectos na proposição de Landowski para uma semiótica das interações que parecem impactar os estudos dos processos de significação da arte contemporânea e, por conseguinte, o que o próprio campo do Design vem desenvolvendo. O primeiro deles é a ruptura com o quadro inicial previsto numa abordagem essencialmente narrativa, em que se pretendia descrever os sentidos produzidos pelos textos (obras ou objetos) a partir de um olhar objetificante sobre os sujeitos em relação. O constrangimento de tal perspectiva começa, segundo Landowski, por reconhecer que as interações humanas (seja com a arte, com objetos do design, com artefatos da moda, ou com qualquer outra forma de manifestação estética) não são regidas apenas pela intencionalidade dos actantes, mas podem estar submetidas à ordem do acaso e do sensível. Em outras palavras, e de forma diversa do que acontece por exemplo em narrativas construídas por autores, os sujeitos do mundo não compõem textos, mas estão mais precisamente envolvidos em situações. Daí a necessidade de ultrapassar a chamada semiótica dos discursos enunciados (e dos textos), na direção de uma sociossemiótica ou semiótica das práticas sociais. O segundo aspecto a considerar é que o autor vislumbra como escapatória um modelo mais amplo de regimes de sentido, passando a buscar um modelo geral para as interações humanas, o que implica pensar além das formas de manipulação previstas na gramática narrativa. Aqui, intervém a sensibilidade dos sujeitos, tomados

6 Artigo de Ana Claudia Oliveira "Convocações Multissensoriais da Arte no Século XX" In PILLAR, Analice Dutra (Org.) A Educação do olhar no ensino das artes. Porto Alegre: Ed.Mediação, 1999. 
não mais enquanto papéis narrativos, mas pelo conjunto de competências inteligíveis e sensíveis convocadas na dinâmica da produção do sentido.

É importante reconhecer a possibilidade de pensar a arte contemporânea a partir destes dois níveis de problematização, ou seja, a partir das estratégias discursivas e a partir da sensibilidade. A vantagem introduzida por Landowski (e também por outros autores da sociossemiótica) parece residir em tomar a interação com os objetos artísticos pelo conceito de apreensão, e não mais de leitura, na medida em que se permite investigar as formas imanentes de experiência do objeto artístico.

Sandra Ramalho - Em especial, o conceito de "acidente do cotidiano" é caro à semiótica da qual se fala, por seu potencial de geração de sentidos, no qual a interação é o ingrediente que amalgama o processo; aí talvez resida a chave para que professores e pesquisadores se deem conta do potencial dessa semiótica para o estudo da arte contemporânea; o que lhes parece?

Moema Rebouças - Não consigo pensar no conceito de "acidente do cotidiano" separado dos demais regimes de interação em termos de importância para a geração de sentido. Considerando a vida cotidiana e as práticas, elas estão imersas e interconectadas no mundo e, portanto, suscetíveis às mudanças, tais como as previstas numa sintaxe da interação que considera as possibilidades das transformações e passagens de um regime a outro. Não são posições fixas, mas intercambiáveis. Por outro lado, considero importante a formação na teoria semiótica, desde a base greimasiana, ou seja desde a compreensão do percurso gerativo de sentido aos regimes de interação como fundamentais para a construção de competências do pesquisador e do professor de artes. Entretanto, compreendo que a Arte Contemporânea ao se destituir do "objeto" e assumir um posicionamento de uma prática de vida, corre os riscos contidos no princípio da casualidade e sendo assim, transgride os esquemas actanciais conhecidos. Rompe com o programado, com o intencional e com o ajuste de sensibilidades para constituir-se como um corte, uma ruptura. Mas o semioticista ao empreender sua análise deve estar atento, se o que a Arte faz parecer ser uma ruptura não é uma estratégia programada de interação com o que com ela vai interatuar.

Murilo Scóz - Acredito que a principal vantagem do encontro com as proposições interacionais de Landowski seja o reconhecimento de um indivíduo dotado não apenas de competências cognitivas e capacitado ao reconhecimento de um mundo inteligível, mas competencializado enquanto sujeito estésico. Ao tratar de arte, e em especial de arte contemporânea, parece natural a um professor (seja do nível que se trate) sensibilizar seus alunos (seus destinatários) ao que é próprio do objeto artístico e que não se pode descrever por um olhar utilitário. Assim, podem nascer propostas pedagógicas que ao invés de manipular os alunos para "saber" a arte (pela costumeira intimidação das avaliações), fazem reverberar a experiência estética pelo estímulo do que Landowski chamou de disponibilidade ao sentido. Claro, parece bastante apropriado pensar que a arte contemporânea também opera neste registro do tensionamento dos cânones, da fuga da institucionalidade e, por conseguinte, da aproximação com o cotidiano. E muito apropriado também parece pensar tais deslizamentos do 
artístico a partir do conceito de acidente ou do consentimento (Landowski, 2017), dado que tanto a sociossemiótica quanto a arte contemporânea são tributárias da problemática do ato e da presença dos corpos sujeitos. Entretanto, um dos maiores benefícios desta modelização das interações a partir de níveis distintos de previsibilidade, é a configuração em forma elíptica assumida pelas interações, o que sugere que ao invés de um único tipo de regime, os sujeitos se engajam no trânsito entre regimes, que se articulam sem um esquema prévio.

Analice Pillar - O conceito de "acidente cotidiano" diz respeito a um modo de interação regido pelo acaso, por algo inusitado, imprevisto, inesperado que ocorre e acaba por mudar o curso dos acontecimentos. Em Da Imperfeição, Greimas trata das fraturas, de acidentes que rompem com o ordinário, com o esperado e que aguçam nossos sentidos. Ao dar continuidade a esta concepção de Greimas, Landowski desdobra os regimes de interação e sentido em quatro - programação, manipulação, ajustamento e acidente - e traz a proposta de um sentido sentido, como um modo de apreensão da significação através dos canais sensoriais, do sensível. A arte contemporânea explora este tipo de interação sensível em que algo inesperado acontece e surpreende o participante, tanto de forma eufórica, com algo agradável, como disfórica, com o que causa repulsa. Ao criar uma obra em processo, em que o público é chamado a participar da sua criação, o artista propõe uma interação que se abre ao acaso, ao inesperado e ao mesmo tempo procura provocar experiências sensiveis que mobilizem os sentidos para que a significação se constitua como um sentido sentido.

Sandra Ramalho - Caros, cada um em seu espaço geográfico e disciplinar, mas com uma epistemologia em comum, vocês têm orientado trabalhos de mestrado e doutorado plenos de possibilidades para a apreensão dos sentidos de criações as mais diferentes, estudos que muitas vezes se restringem aos meios acadêmicos, o que é uma lástima. Vocês poderiam enumerar alguns dos seus orientandos ou ex-orientandos e respectivas temáticas e/ou questões de pesquisa e ainda, se possível, alguns resultados?

Analice Pillar - Desde 1995 venho orientando teses e dissertações no Programa de Pós-Graduação em Educação da Faculdade de Educação da Universidade Federal do Rio Grande do Sul. Nesses 23 anos orientei 26 teses e 24 dissertações. No final de 1990, conheci os trabalhos de semiótica discursiva através do Centro de Pesquisa Sociossemióticas (CPS) da Pontifícia Universidade Católica de São Paulo (PUC-SP), sob a direção de Ana Claudia de Oliveira (PUC-SP) e Eric Landowski, diretor do Centro de Pesquisa em Ciências Políticas de Paris (CNRS - FNSP - CEVIPOF). Esses estudos permitiram um giro conceitual em nossas pesquisas sobre leitura de imagens. A semiótica discursiva desenvolvida por Greimas tem proporcionado as bases teóricas e metodológicas para a análise em profundidade da produção de efeitos de sentido em nossas interações com as imagens da arte, dos meios de comunicação e da vida cotidiana. $O$ foco dos trabalhos se voltou, então, para a análise do percurso gerativo e para os regimes de visibilidade, interação e sentido em textos visuais, audiovisuais e sincréticos. Dentre esses trabalhos alguns enfocaram a literatura infantil, outros as produções sincréticas, as interações com a arte contemporânea, o currículo e a apre- 
ensão estética. Passarei, a seguir, a elencar alguns dos resultados dessas pesquisas que, em quase sua totalidade, se encontra disponível on-line.

\section{Literatura infantil}

Os trabalhos que tiveram por objeto empírico livros de literatura infantil 7 procuraram analisar o percurso gerativo de sentido ampliando o entendimento sobre a problemática da leitura tanto em livros constituídos só por imagens quanto de textos sincréticos, que entrelaçam imagens e textos verbais. Tais trabalhos trouxeram subsídios para os professores sobre a natureza das linguagens verbo-visual e suas implicações nos processos de leitura. E, ainda, definiram alguns princípios para uma abordagem de letramento visual que tenha o livro de imagem como objeto e a leitura mediada como ação. Os resultados desses trabalhos apontam alguns subsídios de como podemos mediar a interação entre sujeitos na leitura de livros de literatura infantil e livros-brinquedo em sala de aula e como os pais podem escolhê-los para seus filhos. Também foi possível evidenciar como se faz importante o ensino da leitura de textos imagéticos na escola numa sociedade em que a imagem está presente a todo o momento, mas que pouco se reflete sobre o que é mostrado e como é mostrado.

\section{Produções sincréticas}

As teses e dissertações ${ }^{8}$ em que o corpus de análise foram produções audiovisuais da mídia e da arte, livros de artistas ou fanzines procuraram pesquisar as relações entre as diversas linguagens envolvidas nesses trabalhos e os efeitos de sentido que possibilitaram. Os efeitos de sentido produzidos por meio dos processos de sincretização das diferentes linguagens foram estudados através das estratégias de montagem ou de editoração utilizadas nessas criações. Tais trabalhos fomentaram reflexões acerca do desenvolvimento de competências e estratégias para a apreensão de sentidos em produtos audiovisuais e verbovisuais; problematizaram a leitura dessas criações no ensino da arte; buscaram compreender os regimes de interação envolvidos. Os resultados dessas pesquisas trouxeram contribuições para as áreas da educação, em geral, e do ensino de artes visuais, em especial, ao evidenciarem as complexas interrelações entre as linguagens num texto sincrético e possibilidades de leituras. Além disso, se debruçaram sobre produções sincréticas como potentes materiais para experimentação expressiva e conceitual,

\footnotetext{
$7 \quad$ PANOZZO, Neiva Senaide Petry. Leitura no entrelaçamento de linguagens: literatura infantil, processo educativo e mediação. 2007. 0 f. Tese (Doutorado em Educação) - Universidade Federal do Rio Grande do Sul. PANOZZO, Neiva Senaide Petry. Percursos estéticos na literatura infantil: contribuições para a leitura de imagens na escola. 2001. 0 f. Dissertação (Mestrado em Educação) - Universidade Federal do Rio Grande do Sul. NUNES, Marília Forgearini. Leitura mediada do livro de imagem no Ensino Fundamental: letramento visual, interação e sentido. 2013. Tese (Doutorado em Educação) - Universidade Federal do Rio Grande do Sul. EVALTE, Tatiana Telch. Para entender o livro-brinquedo: arte e literatura na infância. 2014. Dissertação (Mestrado em Educação) - Universidade Federal do Rio Grande do Sul.

8 POZZI, Marion Divério Faria. Apreensão de sentidos em vídeos contemporâneos: contribuições teórico-metodológicas da semiótica à leitura de recursos de aprendizagem audiovisuais. 2013. Tese (Doutorado em Educação) - Universidade Federal do Rio Grande do Sul. MEDEIROS, Rosana Fachel de. Bob Esponja: Produções de sentidos sobre infâncias e masculinidades. 2010. Dissertação (Mestrado em Educação) - Universidade Federal do Rio Grande do Sul. LERM, Ruth Rejane Perleberg. Leitura de textos sincréticos verbovisuais: relações entre linguagens em (fan) zines brasileiros. 2017. Tese (Doutorado em Educação) - Universidade Federal do Rio Grande do Sul. LERM, Ruth Rejane Perleberg. Leitura de textos sincréticos: relações entre o verbal e o não-verbal em Diário de Bordo de José Bessa. 2010. Dissertação (Mestrado em Educação) - Universidade Federal do Rio Grande do Sul. FROTA, Ana Laura Rolim da. 0 sincretismo nas imagens móveis: DVD "O Universo da Arte - Fayga Ostrower". 2008. Dissertação (Mestrado em Educação) - Universidade Federal do Rio Grande do Sul. CONCEIÇÃO, Simone Rocha da. "De 'O Incrível Mundo de Gumball' à Glitch Arte: competências e estratégias para apreensão de produções audiovisuais em contextos educativos". 2018. Dissertação (Mestrado em Educação) - Universidade Federal do Rio Grande do Sul.
} 
proporcionando subsídios teóricos e metodológicos, a partir da semiótica discursiva, para professores e pesquisadores no campo da leitura de imagens.

\section{Interação com arte contemporânea}

Os trabalhos que enfocaram, em especial, as relações com produções da arte contemporânea ${ }^{9}$ buscaram considerar a interação com tais criações como uma experiência sensível e inteligível, observando a recorrência de sentidos específicos apoiados em princípios fundamentais da experiência estética com a arte contemporânea. A compreensão construída em torno da percepção dos sentidos produzidos na interação com a arte contemporânea foi analisada, em algumas pesquisas através do percurso gerativo de sentido e, em outras, através dos regimes de interação. As pesquisas em que o corpus estava constituído pelos discursos e pelas práticas de mediação em espaços museais analisaram as possibilidades de interação propiciadas por esses espaços tanto às crianças pequenas como ao público em geral. Os resultados apontaram que, em relação aos discursos sobre mediação, nas instituições analisadas, houve predominância dos regimes de programação e de manipulação, em especial de estratégias de sedução; e quanto às práticas foram observados tanto o regime da programação, como os regimes do ajustamento e do acidente. As conclusões evidenciaram que, em algumas das instituições analisadas, houve consonância entre discursos e práticas e, em outras, houve dissonância entre discursos e práticas. Ainda, quanto aos discursos e às práticas museais voltadas às crianças pequenas foi feita uma proposta de trabalho colaborativo entre profissionais da educação infantil e profissionais de um museu. Os resultados ressaltaram a importância de uma formação cultural, inserida no processo de formação continuada, como uma possibilidade de desenvolvimento profissional de professores da infância e de profissionais do museu.

\section{Currículo}

As pesquisas que tiveram como objeto empírico o currículo ${ }^{10}$ de cursos superiores de artes visuais buscaram refletir sobre as especificidades do campo das artes como conhecimento e repensar seu ensino num curso superior na universidade. Dentre essas pesquisas, duas delas enfocaram universidades brasileiras, um curso presencial de artes visuais e um curso a distância, e uma analisou o currículo de artes em uma universidade moçambicana. A tese que analisou o currículo de um curso

\footnotetext{
9 FRANÇOIS, Marlene Ramires. Ciranda de arte: leitura de textos/obras tridimensionais da artista Katsuko Nakano. 2006. Tese (Doutorado em Educação) - Universidade Federal do Rio Grande do Sul. LEDUR, Rejane. Arte Contemporânea e Produção de Sentidos no Ensino da Arte. 2013. Tese (Doutorado em Educação) - Universidade Federal do Rio Grande do Sul. BON, Gabriela. Discursos e Práticas de Mediação em Espaços Museais no Brasil e na Espanha: Bienal de Artes Visuais do Mercosul, Museo del Prado e Espacio Fundación Telefónica. 2016. Tese (Doutorado em Educação) - Universidade Federal do Rio Grande do Sul. BON, Gabriela. Mediação Profissional em Instituições Museais de Porto Alegre: interações discursivas. 2012. Dissertação (Mestrado em Educação) - Universidade Federal do Rio Grande do Sul. GABRE, Solange de Fátima. Para Habitar Museu com o Público Infantil: uma proposta de formação colaborativa entre professores da infância e profissionais do Museu Municipal de Arte de Curitiba. 2016. Tese (Doutorado em Educação) - Universidade Federal do Rio Grande do Sul.

10 BARRETO, Umbelina Maria Duarte. Espiando pelo buraco da fechadura: o conhecimento em artes visuais em nova chave. 2008. 0 f. Tese (Doutorado em Educação) - Universidade Federal do Rio Grande do Sul. COSSA, Lourenço Eugénio. Processos de significação dos conhecimentos em arte no ensino em Moçambique. 2013. Tese (Doutorado em Educação) - Universidade Federal do Rio Grande do Sul. ARMANDO, Elisete Silva. 0 papel do tutor a distância no curso de Licenciatura em Artes Visuais EaD: interação e efeitos de sentido. 2017. Dissertação (Mestrado em Educação) - Universidade Federal do Rio Grande do Sul.
} 
presencial abordou as mudanças paradigmáticas do conhecimento das Artes Visuais, que contribuem para a inserção/aceitação da diferença da arte na universidade, em um quadro sistêmico que inclui mudanças da sociedade geradas pelo acoplamento do sistema cultural. A dissertação que analisou um curso de artes visuais a distância buscou conhecer os efeitos de sentido produzidos na interação da tutoria com os discentes, no ambiente virtual de aprendizagem, através dos fóruns. Nos discursos analisados dos fóruns o foco estava nos mecanismos de produção de sentido na prática das interações através da mediação digital, identificando tais discursos com os regimes de interação. Na tese sobre o currículo de artes visuais numa universidade de Moçambique o foco foi a apreensão dos efeitos de sentido que circulavam na prática docente das disciplinas referentes às artes visuais, visando refletir acerca das relações entre educação, arte e conhecimento.

\section{Apreensão estética}

Muitos dos trabalhos mencionados anteriormente foram atravessados por apreensões estéticas, seja nos livros de literatura infantil, nos livros-brinquedo, nos livros de artistas, nos fanzines, nas produções visuais, audiovisuais, verbovisuais da mídia e da arte contemporânea, nos discursos e nas práticas de mediação, nos currículos de cursos superiores de artes visuais. Dois, no entanto, tiveram por foco, especificamente, as experiências estéticas na formação de pedagogos ${ }^{11}$. Uma tese investigou a relação entre experiências estéticas e prática docente com linguagens artísticas, narradas em memoriais produzidos por professores da educação da infância, num Curso de Especialização em Ensino de Arte e Educação Física na Infância, desenvolvido pelo Paideia/UFRN. As conclusões indicaram que as experiências estéticas vivenciadas pelos professores, em ambientes não formais e informais, influenciaram propostas com linguagens artísticas na sala de aula, tanto de criação como de leitura de produções da arte, de seu cotidiano e do ambiente. E mostraram, também, a importância de considerar a dimensão estética na formação de professores da infância. A outra tese, que se encontra em andamento, está tratando da leitura de imagens, com foco na apreensão estética, na formação do pedagogo.

Todas essas pesquisas tiveram como objeto teórico a leitura, como apreensão de efeitos de sentido, numa diversidade de objetos empíricos (livros de literatura infantil, livros-brinquedo, livros de artistas, fanzines, produções visuais, audiovisuais, verbovisuais da mídia e da arte contemporânea, discursos e práticas de mediação, currículos de cursos superiores de artes visuais, experiências estéticas) e buscaram contribuir para o ensino da arte, em especial, e para a educação, de modo mais amplo.

Moema Rebouças - Ingressei no Programa de Pós-Graduação em Educação da UFES, em 2001 e desde então tenho orientado as dissertações e teses com os alicerces da semiótica com o objetivo de contemplar os estudos da Arte, da Educação e da Comunicação. Uma síntese destes estudos será exposta a seguir e para tanto, consi-

11 PONTES, Gilvânia Maurício Dias de. Arte na educação da infância: saberes e práticas da dimensão estética. 2013. Tese (Doutorado em Educação) - Universidade Federal do Rio Grande do Sul. EVALTE, Tatiana Telch. (Re) pensando as artes visuais na formação do pedagogo: estratégias para a leitura de imagem. Início: 2015. Projeto de Tese (Doutorado em Educação) - Universidade Federal do Rio Grande do Sul. 
derar-se-á num recorte necessário, dado ao quantitativo ${ }^{12}$, agrupando as pesquisas em quatro grandes temáticas, a saber: a formação do leitor a partir de diferentes textos; as práticas de vida e a significação do espaço, as interações entre sujeitos mediadas pela tecnologia e as artes e seu ensino.

\section{A formação do leitor a partir de diferentes textos}

Nas pesquisas reunidas em torno desta temática $A$ formação do leitor a partir de diferentes textos ${ }^{13}$ estão aquelas que analisaram materiais destinados à educação, tais como os livros didáticos, periódico didático e programas destinados às escolas. São estudos que têm como objeto mídias sociais impressas e audiovisuais, como por exemplo, as revistas destinadas ao público adolescente, um programa de televisão para o público infantil e o uso da tecnologia virtual pela escola e adolescentes. Nelas a semiótica contribuiu como aporte metodológico nas etapas de descrição e análise das produções "escolares" e midiáticas que organizam e estruturam a prática docente e a aprendizagem dos estudantes tanto na escola como fora dela. Para justificar a realização destas pesquisas, um forte argumento está no próprio conceito de leitura que é legitimado nas escolas, qual seja, o do sistema verbal. O estudo da leitura da imagem, quando é realizado nas escolas fica à cargo da disciplina de Artes, portanto, o sistema visual e/ou audiovisual como textualidade significante, e como portador de conhecimento é pouco explorado.

Ainda nessa temática, num sub-grupo que toma como objeto mídias impressas e audiovisuais e destinadas ao público infantil e adolescente, estão pesquisas de desenhos animados, das revistas Capricho e Atrevida, de audiovisuais destinados a combater o trabalho infantil, entre outras produções.

A importância do ensino da leitura dos textos da TV, revistas e outras mídias está na carga ideológica/poder de informação com que carrega a enunciação. Desse modo, os estudos sobre televisão, criança e educação com a abordagem semiótica possibilitaram contribuições para a leitura e para o desvelamento dos mecanismos dessa grande tela de sentidos - a televisão. Por outro lado, a análise da Capricho conclui que esta revista se estrutura como uma cartilha que educa a adolescente a partir da relação entre uma plasticidade rica e de uma verbalidade extraída do enunciar jovem. Nesse atuar sincrético, submete a leitora aos valores sociais destinados à mulher brasileira, tais como: amabilidade, sociabilidade atrelada à estética e a importância dos estudos para o mercado de trabalho. Todos embasados nos modos do parecer que têm nas propostas de consumo, inseridas em suas seções, a

\footnotetext{
12 Nesse período até 2017 orientei 23 dissertações de mestrado e 9 teses de doutorado. Atualmente tenho 2 mestrandos, 4 doutorandas e uma supervisão de pós-doutorado. Atuei também no Programa de Pós-Graduação em Comunicação da UFES de 2013 a 2015.

13 GOBETTI, E.(2004). A produção de sentido na relação texto verbal e visual no programa Veja na sala de aula. SILVA, Ivete Aparecida. (2004). Textos verbais/visuais no livro didático de língua portuguesa: uma análise dos mecanismos de construção de sentido e da leitura proposta. ZACHÉ, Maria Aparecida. (2009). Produção de sentido por meio de manifestações imagéticas no livro de Geografia. CASTRO, Juliana. (2013). O Discurso Da Nova Escola: Procedimentos e Valores. Todas do (Mestrado em Educação) - Programa de Pós-Graduação em Educação, Universidade Federal do Espírito Santo, Vitória. SALLES, Marilene (2012). Valores Em Circulação: A Gazeta Na Sala De Aula. Tese. (Doutorado em Educação) - Programa de Pós-Graduação em Educação, Universidade Federal do Espírito Santo, Vitória. PIROLA, Maria Nazareth Bis. (2006) Televisão, Criança e Educação: As Estratégias Enunciativas de Desenhos Animados. ABREU, Tânia. (2007). Interação Entre Adolescentes e Propagandas: Uma Educação para Mídia. JANTORNO, Alessandra. (2008). 0 Discurso do Trabalho Infantil E da Escola: (Re) Significando Sentidos e Descobrindo Intertextualidades. Todas (Mestrado em Educação) - Programa de Pós-Graduação em Educação, Universidade Federal do Espírito Santo, Vitória. MESQUITA, Letícia A Cartilha Midiática de Capricho para a Educação da Jovem Brasileira (Doutorado em Educação) - Programa de Pós-Graduação em Educação, Universidade Federal do Espírito Santo, Vitória.
} 
mola propulsora para fazer-crer à leitora ser ela a sua destinadora. A relevância da tese também está em mostrar que as análises das relações entre o visual e o verbal escrito são essenciais para a apreensão da significação de um texto sincrético e na construção de um sujeito-leitor crítico.

\section{Práticas de vida e a significação do espaço}

No segundo grupo temático ${ }^{14}$ estão reunidas as pesquisas que envolvem situações e práticas vividas em determinado local, ou suporte de linguagem (como o digital).

São pesquisas em que o espaço escolar é composto não somente por uma estrutura física e arquitetônica, ou das legislações que o normatizam, mas de práticas cotidianas que o engendram, o articulam e o constituem, assim como aos sujeitos que ali transitam. As abordagens dessas pesquisas questionam a significação do espaço escolar, considerando que o espaço significa e analisando o que ele significa. Para tanto, foi necessário conceber a espacialidade como constituidora de sentido na organização e desenvolvimento dos múltiplos aspectos que povoam a aprendizagem.

Tendo como fio metodológico integrador os regimes de interação propostos por Landowski $(1992,2002,2014)$, estas investigações nos aproximam do espaço do vivido e do sentido dos sujeitos em interação, e possibilitam a criação de um percurso analítico que é constituído com o Outro, ou seja, "com" crianças e adolescentes, e não "sobre" crianças e adolescentes. Ao mesmo tempo, nos possibilitam compreender, como a arquitetura de um prédio como o de uma escola, abriga outras estruturas móveis e cambiantes que instauram práticas sociais e educativas distintas neste mesmo espaço.

Esta saída do "texto" compreendido em seu sentido estrito, de uma semiótica restrita a um método de análise de conteúdo, para uma abordagem que abrange o conjunto de sistemas de significação considera que a "vida social" se constitui e se manifesta como processo de significação. Como uma semiótica da situação, e não unicamente do "texto", a sociossemiótica utiliza o conceito de enunciação, que é da ordem do discurso, como "ato" que faz agir e faz ser o sujeito, pois o discurso é dinâmico, processual e gerativo. Se mesmo a leitura de um texto em sentido estrito, tal como um conto, uma pintura, ou de um artigo de jornal, considera "o crivo de leitura do mundo" do leitor, o seu posicionamento e valores de mundo e de sociedade, a leitura de uma prática, ou de uma situação emergirá das relações entre sujeitos e entre sujeitos e objetos e abrangem, ao mesmo tempo, o contexto em que ocorrem (espacial, temporal). Envolvem a organização e a circulação dos valores e objetos significantes que o discurso social manipula e produz.

\footnotetext{
14 ROSSONI, Rodrigo. (2004). Fotografia e construção de identidade de criança do MST: o sentido vivido a partir de uma prática educativa. (Mestrado em Educação) - Programa de Pós-Graduação em Educação, Universidade Federal do Espírito Santo, Vitória. MAGRO, A. (2010). A significação do Espaço Escolar. ZANIN, Larissa. (2012). Fotografia E Interação: Modos de Apresentação Do Adolescente E Da Escola No Ciberespaço. Tese. (Doutorado em Educação) - Programa de Pós-Graduação em Educação, Universidade Federal do Espírito Santo, Vitória.
} 


\section{As interações entre sujeitos mediadas pela tecnologia}

$\mathrm{Na}$ terceira grande temática estão reunidas três pesquisas ${ }^{15}$ que tomam como corpus o Curso de Licenciatura em Artes Visuais, na modalidade da educação à distância iniciado em 2009 na Universidade Federal do Espírito Santo. A primeira elege como objeto de estudo o próprio curso para compreender as concepções de professor que nortearam/embasaram o currículo proposto e a análise dos processos de aprendizagem disponibilizados no Ambiente Virtual (AVA); a segunda a presença do professor em vídeos tutoriais e as mediações nesse ambiente na oferta de uma das disciplinas, e o processo de formação desse aluno/professor em formação.

Como estudos de caso, estas pesquisas elegem o Ambiente Virtual de Aprendizagem do Curso-AVA, como principal foco descritivo e analítico da investigação. O embasamento na semiótica possibilitou a apreensão dos sentidos presentes nos discursos e nas práticas educativas do/no ambiente virtual para a compreensão de como o conhecimento ocorre, num primeiro momento, sem a necessidade da relação presencial entre o professor e o aluno. $O$ estudo das narrativas nas três pesquisas possibilitaram a apreensão dos valores e das persuasões inscritas nos processos de ensino aprendizagem que circulam no AVA. Concluem que é por meio dessa interação, mediada pelo AVA, que os sujeitos envolvidos constroem suas ações e seus atos a partir de cada deslocamento e participação nesse ambiente virtual, remodelando e redefinindo suas práticas. Rompem com as regularidades previstas nos documentos, instauram outros modos de aprendizagem e de ser professor e de ser aluno nesse ambiente. Na análise dos vídeos tutoriais, a conclusão é que este material didático, segue e reproduz a tradicional comunicação professor - aluno. As formações ideológicas do saber reproduzem a postura docente verticalizada e tradicional da sala de aula, na qual o professor se posiciona "de pé" em frente aos alunos, que "sentados", ouvem a aula expositiva que se sucede. Entretanto, a fala é feita para um aluno solitário que está do outro lado da tela, em circunstâncias de tempo e espaço distintas do coletivo espaço de uma sala de aula presencial. Outras conclusões destas pesquisas orientaram as mudanças na segunda oferta deste curso na UFES.

\section{Artes, e/ou as Artes e seu ensino}

No quarto grupo ${ }^{16}$ estão reunidas pesquisas que tomaram como objeto um espaço de Arte Contemporânea para analisar, desde a montagem de uma exposição às implicações entre o artistas, as obras e os professores de artes visitantes desse espaço; a segunda analisa como são produzidas imagens fotográficas a partir de processos alternativos para depreender que imagens surgem desse processo, e como a utilização desse procedimento é compreendida pelos sujeitos que as produzem.

15 HAMASAKI, S.M.P. (2012). Cerâmica: interação e produção de sentido na educação a distância. GAMA, L. (2012). Vídeos tutoriais na educação a distância: as presenças do professor. (Mestrado em Educação) - Programa de Pós-Graduação em Educação, Universidade Federal do Espírito Santo, Vitória. SIMÕES, V.L.O. (2013). A formação do professor de Arte na modalidade Educação a Distância - UAB/UFES. Tese (Doutorado em Educação) - Programa de Pós-Graduação em Educação, Universidade Federal do Espírito Santo, Vitória.

16 FONSECA, Maria da Penha. A arte contemporânea na educação básica. 2007. Dissertação (Educação) Universidade Federal do Espírito Santo; GANDINI, Marcelo Mattos. Atelier de Fotografia: estudo de caso de processos alternativos de produção de imagem no atelier de fotografia analógica. 2016. Dissertação (Cursos de Mestrado e Doutorado em Educação) Universidade Federal do Espírito Santo; 
Estão também incluídas aqui três pesquisas ${ }^{17}$ que tomam a metodologia de história de vida para resgatar: Como a Escolinha de Arte de Cachoeiro de Itapemirim (EACI) integrou o movimento Escolinhas de Arte do Brasil (EAB), e qual foi o papel da professora Isabel Braga na disseminação e concretização dessa escolinha? Na segunda pesquisa, a indagação é sobre: O que é ser uma professora do campo? E a terceira intenciona responder a seguinte questão: Como é constituída a docência de uma professora egressa do Curso de Graduação em Artes Visuais - Licenciatura na Modalidade EAD?

A semiótica nestes casos foi empregada nas análises dos documentos, na articulação dialógica textual dos documentos verbais e verbovisuais, e na ênfase nos percursos narrativos (visuais e verbais) recuperados na produção de dados destas investigações. Para Barros (1988) a sintaxe narrativa recompõe o simulacro do fazer do homem que transforma o mundo. Composta por um esquema canônico nela estão compreendidos percursos em que a base é a narratividade e a encenação dos fazeres persuasivos e interpretativos entre os sujeitos, estabelecidos numa relação mediatizada por intermédio da circulação de objetos valor. A partir de modalizações do fazer-fazer, do dever-fazer, e de um poder-fazer, próprios dos regimes da junção (manipulação e programação), o que se instaura na narrativa é uma situação de comunicação persuasiva envolvendo dois sujeitos em interação.

Agradeço muitíssimo a participação de cada um de vocês, assinalando que me considero privilegiada, acompanhando e partilhando seus trabalhos desde há um bom tempo, Analice Dutra Pillar, da UFRGS, membro de minha banca de doutorado, em 1998; Moema Rebouças, da UFES, colega de doutorado nessa mesma época; e Murilo Scóz, que conheci pouco depois disso, como orientando e depois, convivendo como colega na UDESC: o fato é que sua parceira em muitas atividades acadêmicas, eu os admiro como profissionais e pessoas, pois hoje os considero a todos como grandes inspiradores e ainda como amigos. Analice e Moema como pioneiras dessa intersecção semiótica/arte/educação e Murilo, representante da nova geração dos semioticistas da visualidade, inaugurando orientações nos recém-criados Doutorado em Design e Mestrado em Moda.

Sigamos nessa trajetória que para alguns pode parecer uma seita mas, ao contrário, está mais próxima da vida do que se pode supor, todos animados pela semiótica sem nome, porque os sentidos estão em aberto, para serem sentidos e não batizados. 